\title{
Sistema radicular e produtividade de soqueiras de cana-de-açúcar sob diferentes quantidades de palhada
}

\author{
Gisele Silva de Aquino(1), Cristiane de Conti Medina(1), Aquilino Leonel Porteira Junior ${ }^{(2)}$, \\ Lucas Oliveira Santos ${ }^{(2)}$, Ana Carolina Benitez Cunha ${ }^{(2)}$, Deise Akemi Omori Kussaba ${ }^{(2)}$, \\ Jaime Higino dos Santos Júnior ${ }^{(2)}$, Luis Fernando Almeida ${ }^{(2)}$ e Antonio Dias Santiago ${ }^{(3)}$
}

\begin{abstract}
(1)Universidade Estadual de Londrina (UEL), Departamento de Agronomia, Rodovia Celso Garcia Cid, PR-445, Km 380, Caixa Postal 10.011, CEP 86057-970 Londrina, PR, Brasil. E-mail: gisele.s.aquino@hotmail.com, medina@uel.br (2)UEL, Departamento de Agronomia, Caixa Postal 10.011, CEP 86057-970 Londrina, PR, Brasil. E-mail: aquilino-jr@hotmail.com, o.lucaas@gmail.com, anabenitez51@gmail.com, deise.akeemi@hotmail.com, jaime_higino@hotmail.com, luizfernando1992@hotmail.com ${ }^{(3)}$ Embrapa Tabuleiros Costeiros, Caixa Postal 2.013, CEP 5706191 Maceió, AL, Brasil. E-mail: antonio.santiago@embrapa.br
\end{abstract}

Resumo - O objetivo deste trabalho foi avaliar o efeito de diferentes quantidades de palhada sobre o sistema radicular e a produtividade da cana-de-açúcar (Saccharum officinarum), de primeira e segunda soqueiras, em Latossolo Vermelho eutroférrico. Seis tratamentos foram avaliados: 0, $5(25 \%), 10(50 \%), 15(75 \%)$ e $20 \mathrm{Mg} \mathrm{ha}^{-1}(100 \%)$ de palhada e cana-queimada, na primeira e segunda soqueiras. Utilizou-se a cana-de-açúcar 'SP80-1816'. Avaliou-se a massa de raízes a 0,45 e $0,75 \mathrm{~m}$ de distância da linha de plantio, até $0,60 \mathrm{~m}$ de profundidade. Na primeira soqueira, os tratamentos com 50, 75 e 100\% de palhada proporcionaram maior massa radicular até $0,20 \mathrm{~m}$ de profundidade, em comparação aos tratamentos cana-queimada, 0 e $5 \mathrm{Mg} \mathrm{ha}^{-1}(25 \%)$ de palhada. Os tratamentos com 50 e $75 \%$ de palhada proporcionaram produtividades $43 \%$ maiores do que a da cana-queimada (110 Mg ha-1). O tratamento com $10 \mathrm{Mg} \mathrm{ha}^{-1}$ (50\%) foi suficiente para proporcionar aumento da massa radicular e da produtividade da cana-de-açúcar. O sistema radicular e a produtividade da cana-de-açúcar são favorecidos pela mudança do sistema de colheita de cana-queimada para o de cana sob palhada.

Termos para indexação: Saccharum officinarum, biomassa, cana crua, colheita mecanizada, enraizamento, manejo da palhada, produção agrícola.

\section{Root system and productivity of sugarcane ratoon associated to different quantities of straw}

\begin{abstract}
The objective of this work was to evaluate the effect of different amounts of straw on the root system and productivity of sugarcane (Saccharum officinarum), of first and second ratoons, in an Oxisol. Six treatments were evaluated: 0, 5 (25\%), $10(50 \%), 15$ (75\%), and $20 \mathrm{Mg} \mathrm{ha}^{-1}(100 \%)$ straw and burned sugarcane of the first and second ratoons. 'SP80-1816' sugarcane was used. Root mass at 0.45 and $0.75 \mathrm{~m}$ away from the row, and up to $0.60 \mathrm{~m}$ deep was evaluated. In the first ratoon, treatments with 50,75 and $100 \%$ straw provided greater root mass up to $0.20-\mathrm{m}$ depth, in comparison to treatments of burned sugarcane, and 0 and $5 \mathrm{Mg} \mathrm{ha}^{-1}(25 \%)$ straw. The treatments with 50 and $75 \%$ straw had $43 \%$ higher yields than burned sugarcane $\left(110 \mathrm{Mg} \mathrm{ha}^{-1}\right)$. The treatment with $10 \mathrm{Mg} \mathrm{ha}^{-1}$ straw $(50 \%)$ was sufficient to provide increased root mass and productivity of sugarcane. The root system and the productivity of sugarcane are favored by the change of burned-sugarcane harvesting system to sugarcane under straw.
\end{abstract}

Index terms: Saccharum officinarum, biomass, green cane, mechanical harvesting, rooting, straw management, agricultural production.

\section{Introdução}

A colheita mecanizada da cana-de-açúcar é uma prática recentemente adotada pelas principais áreas produtoras do Brasil. Nesse sistema, as folhas secas são trituradas, e os ponteiros são cortados e lançados à superfície do solo, o que forma uma cobertura morta denominada palhada. Apenas na safra 2014/2015, o
Brasil ofertou aos mercados 659 milhões de toneladas de cana, tendo gerado mais de 140 milhões de toneladas de palhada (Acompanhamento da safra brasileira, 2015). No campo, são encontrados valores de 10 a $30 \mathrm{Mg} \mathrm{ha}^{-1}$, o que oscila conforme a variedade e a idade do canavial (Christoffoleti et al., 2007).

A palhada que permanece no solo ocasiona alterações nas condições químicas, físicas e biológicas 
do agroecossistema, tais como: aumento e estabilização da umidade do solo; elevação dos teores de matéria orgânica; alterações de fertilidade e temperatura; incidência de pragas; maior eficácia no controle da erosão; interferência na incidência de luz na superfície do solo; e mudança da flora infestante (Cavenaghi et al., 2007; Garcia et al., 2007; Guimarães et al., 2008; Costa et al., 2011). Essas alterações no ambiente do solo podem interferir na dinâmica de enraizamento e na produtividade final (Souza et al., 2005a; Costa et al., 2011).

O sistema radicular da cana-de-açúcar representa um importante componente de estudo, pois desempenha papel essencial na regeneração das soqueiras, após a colheita, e influencia diretamente a eficiência de absorção dos nutrientes pela planta, a resistência à seca e a tolerância ao ataque de pragas do solo, o que afeta todo o desenvolvimento da cultura. Apesar disso, tem sido frequentemente relegado nas pesquisas, em razão, principalmente, da dificuldade de acesso e de visualização, sobretudo em avaliações em campo.

O crescimento das raízes responde ao ambiente do solo e cria plasticidade na forma, no tamanho e na distribuição do sistema radicular (Smith et al., 2005). Esses componentes são afetados diretamente pela distribuição e disponibilidade da água do solo, o que causa diferenças na capacidade das plantas em explorar os recursos do solo em maior profundidade.

Laclau \& Laclau (2009) observaram que a mortalidade do sistema radicular decorre da condição hídrica a que a cultura está submetida em determinado período de desenvolvimento. Assim, a palhada proporciona um microclima sobre o solo, caracterizado por elevada umidade, restrição da perda de água, estabilidade da temperatura e maior disponibilidade hídrica, o que pode causar alterações no comportamento do sistema radicular ou diminuir a mortalidade das raízes e, assim, contribuir para minimizar a queda de produção de um ciclo para outro, principalmente nos períodos de deficiência hídrica.

Outros autores relataram os efeitos positivos da palhada, com aumento de até $59 \%$ na produção de matéria seca da cana-de-açúcar (Ball-Coelho et al.,1993; Resende et al., 2006). Entretanto, não abordaram qual quantidade seria suficiente para obtenção de tais benefícios, ou qual o efeito da manutenção de menores quantidades de palhada sobre a cultura.
A definição da quantidade mínima de palhada a permanecer no campo constitui importante informação para o setor sucroenergético do país, pois, o excedente pode ser utilizado para a produção de bioetanol ou bioeletricidade, setores que necessitam de grande quantidade desse material. A utilização da palhada juntamente com o bagaço poderia triplicar a produção de etanol, sem a necessidade de aumento da área de plantio, ou poderia produzir até 2020 o equivalente a $15 \%$ do total de energia que se consome no Brasil (Lima \& Natalense, 2010).

O objetivo deste trabalho foi avaliar o efeito de diferentes quantidades de palhada sobre o sistema radicular e a produtividade da cana-de-açúcar (Saccharum officinarum), de primeira e segunda soqueiras, em Latossolo Vermelho eutroférrico.

\section{Material e Métodos}

Este trabalho é proveniente de pesquisa realizada em rede nacional, financiada pela Petrobras e iniciada em 2010. O ensaio foi instalado no município de Bandeirantes, no Estado do Paraná, a $23^{\circ} 06^{\prime} \mathrm{S}, 50^{\circ} 21^{\prime} \mathrm{W}$ e a $440 \mathrm{~m}$ de altitude, em área pertencente à Usina de Açúcar e Álcool Bandeirantes. O clima predominante na região, conforme a classificação de Köppen, é do tipo $\mathrm{Cfa}$, com precipitações médias anuais de $1.300 \mathrm{~mm}$. A insolação média é de 7,14 horas por dia.

O balanço hídrico climatológico (Figura 1) foi calculado de acordo com Thornthwaite \& Mather (1955). Utilizaram-se os dados de temperatura média mensal e de chuva total mensal cedidos pela estação meteorológica do Instituto Agronômico do Paraná (Iapar), Bandeirantes, PR, a três quilômetros do local do experimento. Utilizou-se o valor de $100 \mathrm{~mm}$ como capacidade de água disponível (CAD).

O solo está classificado como Latossolo Vermelho eutroférrico (Santos et al., 2013), de textura argilosa, com $610 \mathrm{~g} \mathrm{~kg}^{-1}$ de argila, $20 \mathrm{~g} \mathrm{~kg}^{-1}$ de silte e $370 \mathrm{~g} \mathrm{~kg}^{-1}$ de areia. As análises químicas do solo foram realizadas nas camadas de $0-0,10,0,10-0,20,0,20-0,40$ e 0,40-0,60 $\mathrm{m}$ de profundidade no perfil, no momento da instalação do experimento, em agosto de 2010 (Tabela 1) conforme Claessen (1997); e as análises de densidade do solo foram feitas em 2012 e 2013, logo após a colheita, nas camadas já mencionadas.

Não houve necessidade de adubação química. Antes do plantio, como prática da usina, aplicaram-se

Pesq. agropec. bras., Brasília, v.50, n.12, p.1150-1159, dez. 2015 DOI: 10.1590/S0100-204X2015001200004 
$70 \mathrm{Mg} \mathrm{ha}^{-1}$ de torta de filtro em área total. Nos anos anteriores, haviam sido aplicados $150 \mathrm{~m}^{3} \mathrm{ha}^{-1}$ de vinhaça, para suprir a quantidade de potássio extraída pela cultura, após a colheita. O solo foi preparado com duas gradagens com discos de 36 polegadas.

No local onde se instalou o experimento, cultiva-se cana de açúcar há 65 anos. Inicialmente, utilizava-se o método de colheita manual, com despalha a fogo. Em 2010, a usina adotou o sistema de colheita mecanizada, tendo utilizado esse método também no local do ensaio.
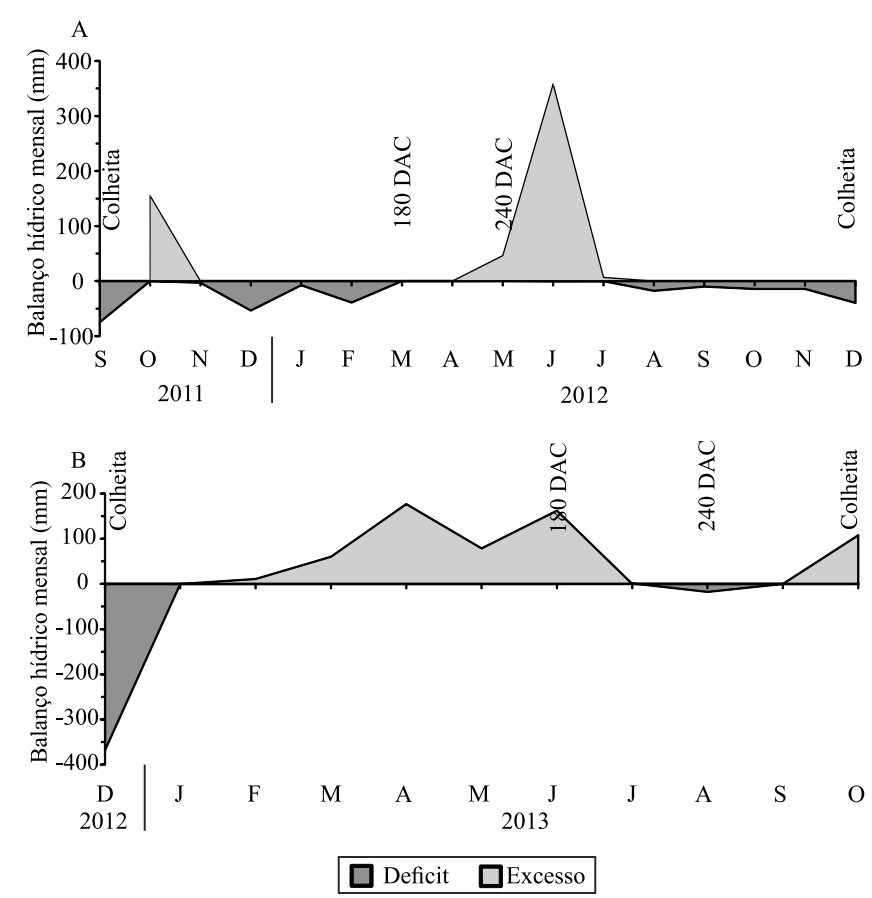

Figura 1. Extrato do balanço hídrico mensal ocorrido durante os ciclos de primeira (A) e segunda soqueiras (B), Bandeirantes, PR. Fonte: Iapar.
O ensaio foi realizado durante dois ciclos da cultura (primeira e segunda soqueiras), em delineamento experimental de blocos ao acaso, com quatro repetições. Cada parcela foi formada de 10 linhas de plantio de cana-de-açúcar com $10 \mathrm{~m}$ de comprimento e espaçamento de $1,5 \mathrm{~m}$ entre linhas, com área de parcela de $10 \times 15 \mathrm{~m}$. Como parcela útil para a coleta dos dados, consideraram-se as seis linhas centrais, tendo-se subtraído $0,50 \mathrm{~m}$ de cada extremidade. Com o início do ciclo, em setembro de 2011, ocorreu o corte da cana-planta; a primeira soqueira foi colhida em dezembro de 2012, e a segunda em outubro de 2013.

A variedade de cana-de-açúcar utilizada foi a 'SP80-1816', muito difundida no centro-sul do Brasil, por apresentar bom perfilhamento e fechamento regular de entrelinhas, alta produtividade agrícola, boa brotação de soqueiras, maturação precoce, alto teor de sacarose, baixo teor de fibra, porte ereto - excelente opção para o corte mecanizado de cana crua, ausência de florescimento e chochamento (Fernandes, 1991).

Seis tratamentos foram avaliados: $0 \%, 5 \mathrm{Mg} \mathrm{ha}^{-1}$ (25\%), $10 \mathrm{Mg} \mathrm{ha}^{-1}(50 \%), 15 \mathrm{Mg} \mathrm{ha}^{-1}(75 \%), 20 \mathrm{Mg} \mathrm{ha}^{-1}$ (100\%) de deposição de palhada e cana queimada, aos 450 (safra 2011/2012) e 300 (safra 2012/2013) dias após o corte (DAC) na primeira e na segunda soqueira, respectivamente. No tratamento com cana queimada, $100 \%$ da palhada foi distribuída sobre a parcela e, em seguida, foi queimada. Em agosto de 2010, logo após o plantio, adicionaram-se no solo as quantidades de palhada correspondentes a cada tratamento, a fim de verificar a brotação e o desenvolvimento da cana-planta sob diferentes quantidades de palhada. No momento da colheita, a palhada produzida em cada ciclo foi acondicionada em sacolas (big bag) de polipropileno de alta resistência, com dimensões

Tabela 1. Atributos químicos do solo (Latossolo Vermelho eutroférrico) cultivado com cana-de-açúcar, nas camadas de 0 a $0,60 \mathrm{~m}$ de profundidade, em agosto de 2010 .

\begin{tabular}{|c|c|c|c|c|c|c|c|c|c|c|c|}
\hline $\begin{array}{l}\text { Camada de solo } \\
(\mathrm{m})\end{array}$ & $\begin{array}{c}\mathrm{MO} \\
\left(\mathrm{g} \mathrm{kg}^{-1}\right)\end{array}$ & $\begin{array}{l}\mathrm{pH} \mathrm{em} \\
\mathrm{CaCl}_{2}\end{array}$ & $\begin{array}{l}\text { P-Mehlich } 1 \\
\left(\mathrm{mg} \mathrm{dm}^{-3}\right)\end{array}$ & \multicolumn{4}{|c|}{ 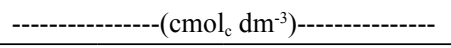 } & \multicolumn{3}{|c|}{---------- Saturação (\%) ---------- } & $\mathrm{Mg}$ \\
\hline $0-0,10$ & 26,8 & 5,4 & 8,6 & 2,50 & 7,8 & 1,7 & 3,1 & 15,1 & 16 & 52 & 11 \\
\hline $0,10-0,20$ & 41,6 & 5,9 & 71,3 & 3,60 & 7,9 & 1,9 & 2,9 & 16,3 & 22 & 49 & 12 \\
\hline $0,20-0,30$ & 34,9 & 6,1 & 31,0 & 3,70 & 8,0 & 2,1 & 3,0 & 16,8 & 22 & 48 & 12 \\
\hline $0,30-0,40$ & 30,9 & 6,2 & 5,1 & 4,60 & 8,1 & 2,1 & 2,2 & 17,0 & 27 & 48 & 12 \\
\hline $0,40-0,50$ & 37,6 & 6,3 & 9,0 & 4,20 & 7,3 & 2,0 & 2,4 & 15,9 & 26 & 46 & 13 \\
\hline $0,50-0,60$ & 28,2 & 6,3 & 5,3 & 3,20 & 6,1 & 2,1 & 2,4 & 13,8 & 23 & 44 & 15 \\
\hline
\end{tabular}


0,90x0,90x1,60 m, pesada em balança digital Nagata modelo HC33 $2 \mathrm{~T}$ e redistribuída sobre a parcela nas quantidades respectivas de cada tratamento. Por estar em processo de decomposição, a palhada remanescente do ciclo anterior diferia visualmente da palhada recém-depositada no solo no momento da colheita e, portanto, não foi incluída na pesagem. Assim, os dados obtidos na primeira e segunda soqueiras de cana-de-açúcar resultaram, respectivamente, em dois e três anos de cultivo sob as quantidades de palhada.

Para avaliação do sistema radicular, no momento da colheita, foram abertas trincheiras nas entrelinhas, com $0,80 \times 1,00 \times 0,80 \mathrm{~m}$ (largura, comprimento e altura, respectivamente) e utilizados cilindros metálicos com $0,074 \mathrm{~m}$ de diâmetro, $0,10 \mathrm{~m}$ de altura e volume de anel de $0,00043 \mathrm{~m}^{3}$ (Azevedo et al., 2011). Os cilindros foram cravados na parede, perpendicularmente à linha de plantio, com auxílio de um esticador hidráulico, a 0,45 e $0,75 \mathrm{~m}$ de distância da linha, às profundidades $0-0,10,0,10-0,20,0,20-0,40$ e $0,40-0,60 \mathrm{~m}$, em quatro repetições por tratamento (Figura 2). Cada repetição foi formada por uma amostra, composta de três amostragens realizadas em cada parcela. Posteriormente, as amostras foram levadas ao Laboratório de Estudo das Raízes, do Departamento de Agronomia, da Universidade Estadual de Londrina.

Cada amostra composta foi colocada em um balde de plástico, com água e agitada manualmente. A água

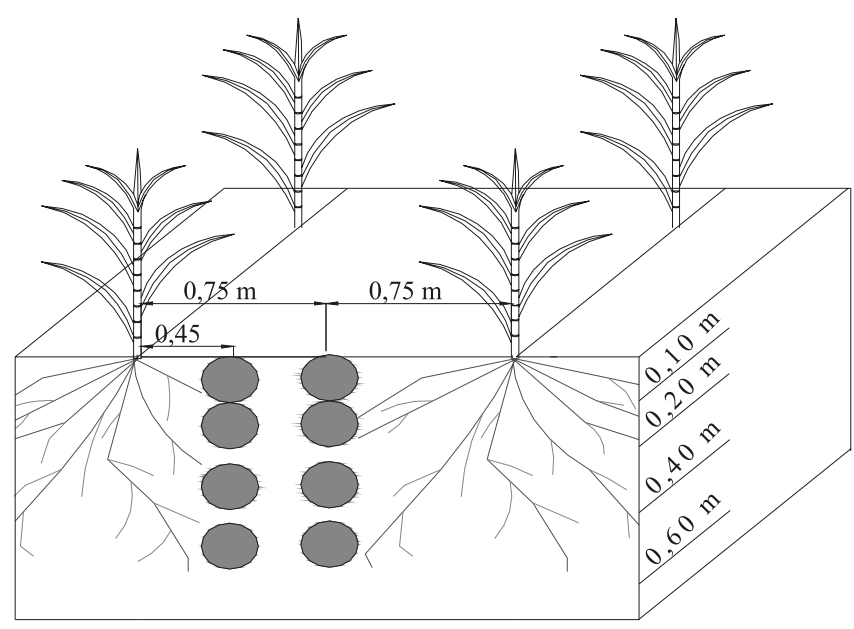

Figura 2. Desenho esquemático das distâncias de retirada de amostras de raízes, a 0,45 e 0,75 $\mathrm{m}$ da linha de plantio de cana-de-açúcar 'SP 801816', das profundidades $(0-0,10$, $0,10-0,20,0,20-0,40$ e $0,40-0,60 \mathrm{~m})$. e as raízes em suspensão foram vertidas em uma peneira de malha de dois milímetros. Essa operação foi repetida até não haver mais terra. Todas as raízes retidas na peneira foram coletadas e levadas à estufa a $65^{\circ} \mathrm{C}$, até a obtenção de massa constante. Depois de secas, as raízes foram pesadas em balança de precisão, e os resultados foram apresentados em miligramas de raízes por centímetro cúbico de solo.

A massa de matéria fresca dos colmos $\left(\mathrm{Mg} \mathrm{ha}^{-1}\right)$ foi avaliada aos 450 DAC (dezembro/2012), na primeira soqueira, e aos 300 DAC (outubro/2013), na segunda soqueira, com a coleta total dos colmos contidos na área útil das parcelas. Retiraram-se dos colmos as folhas verdes e secas, realizou-se o desponte e, em seguida, a pesagem.

Após a colheita de cada ciclo, não se realizou adubação de cobertura e nem cultivo de entrelinha, apenas foram depositadas as respectivas quantidades de palhada de cada tratamento na parcela.

Os resultados foram submetidos à análise de variância, e as médias foram comparadas pelo teste Tukey, a 5\% de probabilidade.

\section{Resultados e Discussão}

Os valores de densidade do solo nas camadas $0-0,10,0,10-0,20,0,20-0,40$ e $0,40-0,60 \mathrm{~m}$ foram, respectivamente: $1,33,1,30,1,30$ e $1,29 \mathrm{~g} \mathrm{~cm}^{-3}$ na primeira soqueira, em 2012; e 1,34, 1,30, 1,30 e $1,30 \mathrm{~g} \mathrm{~cm}^{-3}$ na segunda soqueira, em 2013. Estes valores não são considerados restritivos ao desenvolvimento do sistema radicular nesse solo (Paulino et al., 2004).

Na primeira soqueira (safra 2011/2012), houve efeito da palhada sobre o sistema radicular até os $0,20 \mathrm{~m}$ de profundidade (Figura 3). Deve-se ressaltar a ocorrência de deficiência hídrica até os 180 DAC, exceção de outubro de 2011, e maior disponibilidade hídrica dos 240 aos 270 DAC (Figura 1). Na distância de $0,45 \mathrm{~m}$ da linha de plantio, os tratamentos 10,15 e $20 \mathrm{Mg} \mathrm{ha}^{-1}$ $(50,75$ e $100 \%)$ de palhada apresentaram maior massa de matéria seca de raízes, tanto na camada de $0-0,10 \mathrm{~m}$ (média 0,56 $\mathrm{mg} \mathrm{cm}^{-3}$ ) quanto na de $0,10-0,20 \mathrm{~m}$ (média de $\left.0,52 \mathrm{mg} \mathrm{cm}^{-3}\right)$, tendo diferido dos tratamentos com cana queimada, e 0 e $25 \%\left(5 \mathrm{Mg} \mathrm{ha}^{-1}\right)$ de deposição de palhada que proporcionaram menores médias 0,41 e $0,37 \mathrm{mg} \mathrm{cm}^{-3}$, respectivamente, para a primeira e segunda camadas (Figura 3).

Pesq. agropec. bras., Brasília, v.50, n.12, p.1150-1159, dez. 2015 DOI: 10.1590/S0100-204X2015001200004 

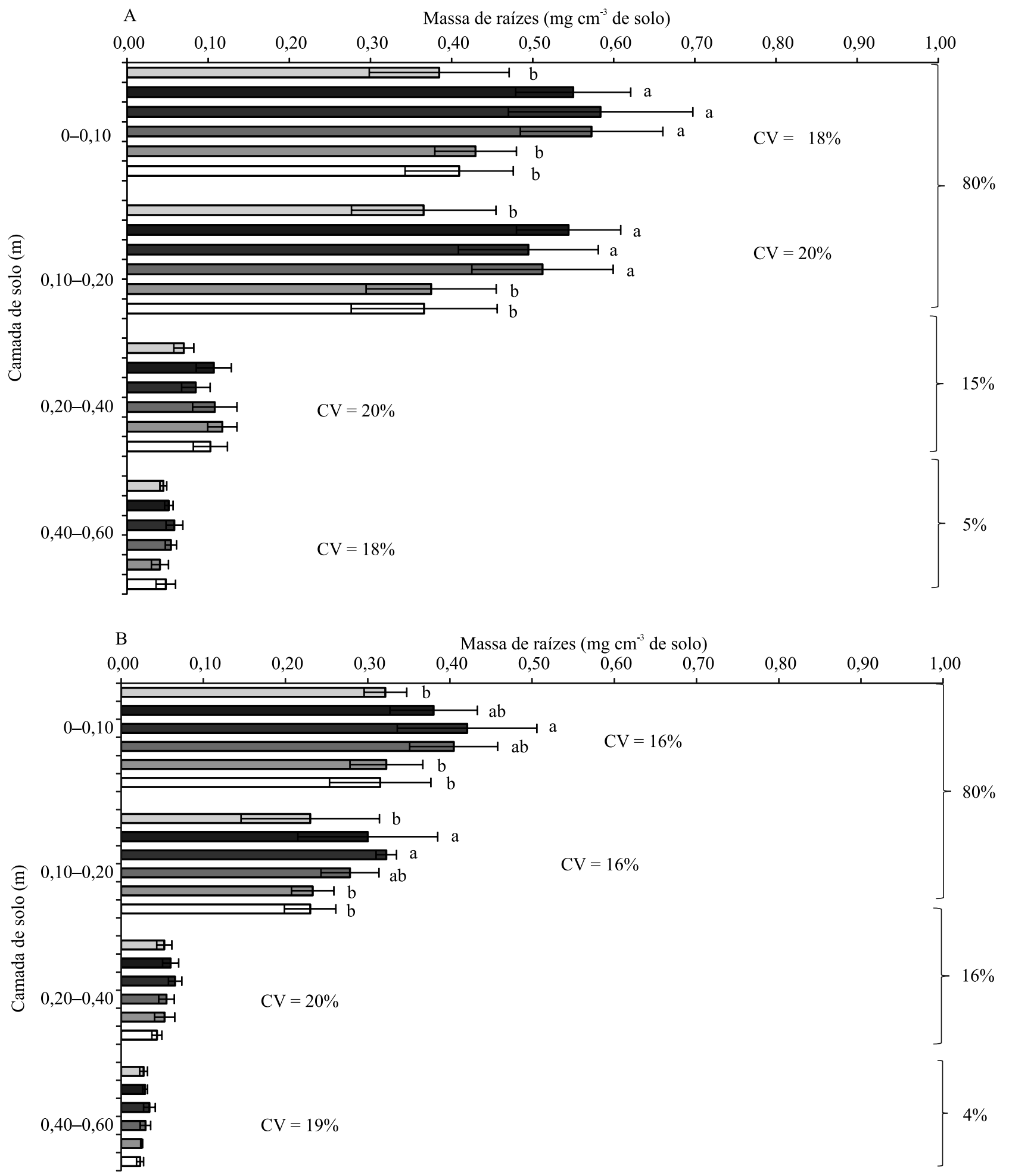

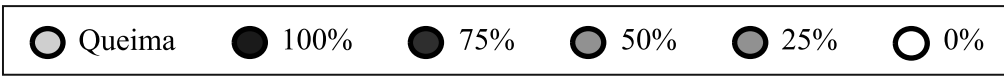

Figura 3. Massa de matéria seca de raízes da primeira soqueira, às distâncias 0,45 (A) e $0,75 \mathrm{~m}$ (B) da touceira, aos $450 \mathrm{DAC}$, nas camadas $0-0,10,0,10-0,20,0,20-0,40$ e $0,40-0,60 \mathrm{~m}$, e percentagem média de distribuição de raízes no perfil avaliado. Médias seguidas de letras iguais não diferem entre si, pelo teste Tukey, a 5\% de probabilidade. 
Na distância de $0,75 \mathrm{~m}$ da touceira, o comportamento foi similar, e na camada de $0-0,10 \mathrm{~m}$, o tratamento com $75 \%$ de palhada apresentou maior massa de raízes $\left(0,42 \mathrm{mg} \mathrm{cm}^{-3}\right.$ de solo) em relação ao de cana queimada, e ao de 0 e $25 \%$ de palhada (média $0,32 \mathrm{mg} \mathrm{cm}^{-3}$ de solo). Na camada $0,10-0,20 \mathrm{~m}$, a deposição de 75 e $100 \%$ de palhada proporcionaram maior massa radicular (média $0,31 \mathrm{mg} \mathrm{cm}^{-3}$ ), em comparação com cana queimada, 0 e $25 \%$ de palhada, que apresentaram média de $0,23 \mathrm{mg} \mathrm{cm}^{-3}$. Pode-se verificar que os tratamentos acima de $50 \%$ de palhada, provavelmente pela manutenção de maior umidade do solo, proporcionaram melhores condições para que o sistema radicular se desenvolvesse, o que resultou em maior massa de raízes.

Laclau \& Laclau (2009) avaliaram o crescimento do sistema radicular de cana-de-açúcar em condições de sequeiro e irrigadas em Latossolo argiloso. Observaram que, em condições de deficiência hídrica, a cana-de-açúcar tem o crescimento de raízes muito lento ou paralisado, além de não conseguir manter a quantidade de raízes já desenvolvidas, o que resulta em grande mortalidade, principalmente das raízes superficiais, e diminuição da massa radicular, o que foi observado no presente trabalho, nos tratamentos com cana queimada, 0 e $25 \%$ de palhada.

A maior taxa de infiltração e retenção de água no solo, com redução da perda de água de aproximadamente $70 \%$, além de menores temperaturas proporcionadas pela palhada, representam importante benefício para a cultura, principalmente em períodos com deficiência hídrica ou precipitação irregular, que ocasionam quedas de produtividade (Souza et al., 2005b).

$\mathrm{Na}$ segunda soqueira, quando, com exceção do período de corte, ocorreu excesso hídrico até 210 DAC (julho de 2013) e pequena deficiência apenas no mês de agosto/2013 (Figura 1 B), observou-se que a massa de raízes foi similar entre os tratamentos em todas as profundidades avaliadas, tanto na distância a 0,45 quanto na de $0,75 \mathrm{~m}$ da linha de plantio (Figura 4).

Alvarez et al. (2000) avaliaram os efeitos do manejo de cana crua e queimada sobre o enraizamento, em um Latossolo Vermelho-Escuro distrófico, e não verificaram diferença significativa nem no primeiro, nem no segundo ano de cultivo, até $0,60 \mathrm{~m}$ de profundidade. Esta ausência de efeito da palhada pode ser decorrente do genótipo, da idade e do ambiente de produção. Os autores relataram que, praticamente em todos os meses, não houve eventos meteorológicos desfavoráveis. Sob condições meteorológicas não muito estressantes às plantas, é provável que o efeito da palhada não seja imediato, diferentemente de regiões ou períodos que apresentam condições menos favoráveis, como observado por Cury et al. (2014) e no presente trabalho (Figura 1A).

A distribuição das raízes (Figuras 3 e 4) no perfil avaliado (até os $0,60 \mathrm{~m}$ de profundidade) foi similar à de outras gramíneas tropicais, com declínio exponencial de massa de raízes em razão da profundidade (Smith et al., 2005).

A profundidade efetiva, que é aquela em que se concentram $80 \%$ das raízes do perfil avaliado, foi de $0,18 \mathrm{~m}$, na primeira soqueira (Figura 3 ), tanto a $0,45 \mathrm{~m}$, quanto a $0,75 \mathrm{~m}$ da linha de plantio. Na segunda soqueira (Figura 4), a profundidade efetiva foi de $0,21 \mathrm{~m}$ e $0,19 \mathrm{~m}$, respectivamente, nas distâncias a 0,45 e $0,75 \mathrm{~m}$ da linha de plantio, o que indica não ter havido alteração em relação à primeira soqueira.

Costa et al. (2007) salientam que diversos estudos, referentes à distribuição vertical de raízes de cana-de-açúcar no perfil do solo, indicaram cerca de 60 a $70 \%$ da quantidade de raízes concentradas nos primeiros $20 \mathrm{~cm}$ de profundidade.

Conforme se pode constatar, é uma característica da cana-de-açúcar ter maior desenvolvimento de raízes na camada 0-0,20 m. Esta camada, por ser superficial, é vulnerável às condições meteorológicas, com influência direta sobre o sistema radicular, o que faz com que a cultura apresente diminuição da produtividade em situações desfavoráveis de ambiente. Laclau \& Laclau (2009) verificaram que a morte ou a renovação das raízes está diretamente ligada à disponibilidade hídrica e à temperatura do solo. Ao cessar a deficiência hídrica, ocorre elevado gasto de energia para a formação de novas raízes (Smith et al., 2005), o que afeta a produtividade final, conforme constatado por Tavares et al. (2010), Aquino \& Medina (2014), Costa et al. (2014) e no presente trabalho.

$\mathrm{Na}$ comparação das massas de matéria seca de raízes da primeira e segunda soqueiras, nota-se que os tratamentos com cana queimada, 0 e $25 \%$ de palhada que tiveram menor massa radicular até os $0,20 \mathrm{~m}$ de profundidade na primeira soqueira, apresentaram maiores valores na segunda soqueira, que teve maior disponibilidade hídrica, tanto na distância a $0,45 \mathrm{~m}$ quanto a $0,75 \mathrm{~m}$ da linha de plantio. Os tratamentos 50 ,

Pesq. agropec. bras., Brasília, v.50, n.12, p.1150-1159, dez. 2015 DOI: 10.1590/S0100-204X2015001200004 

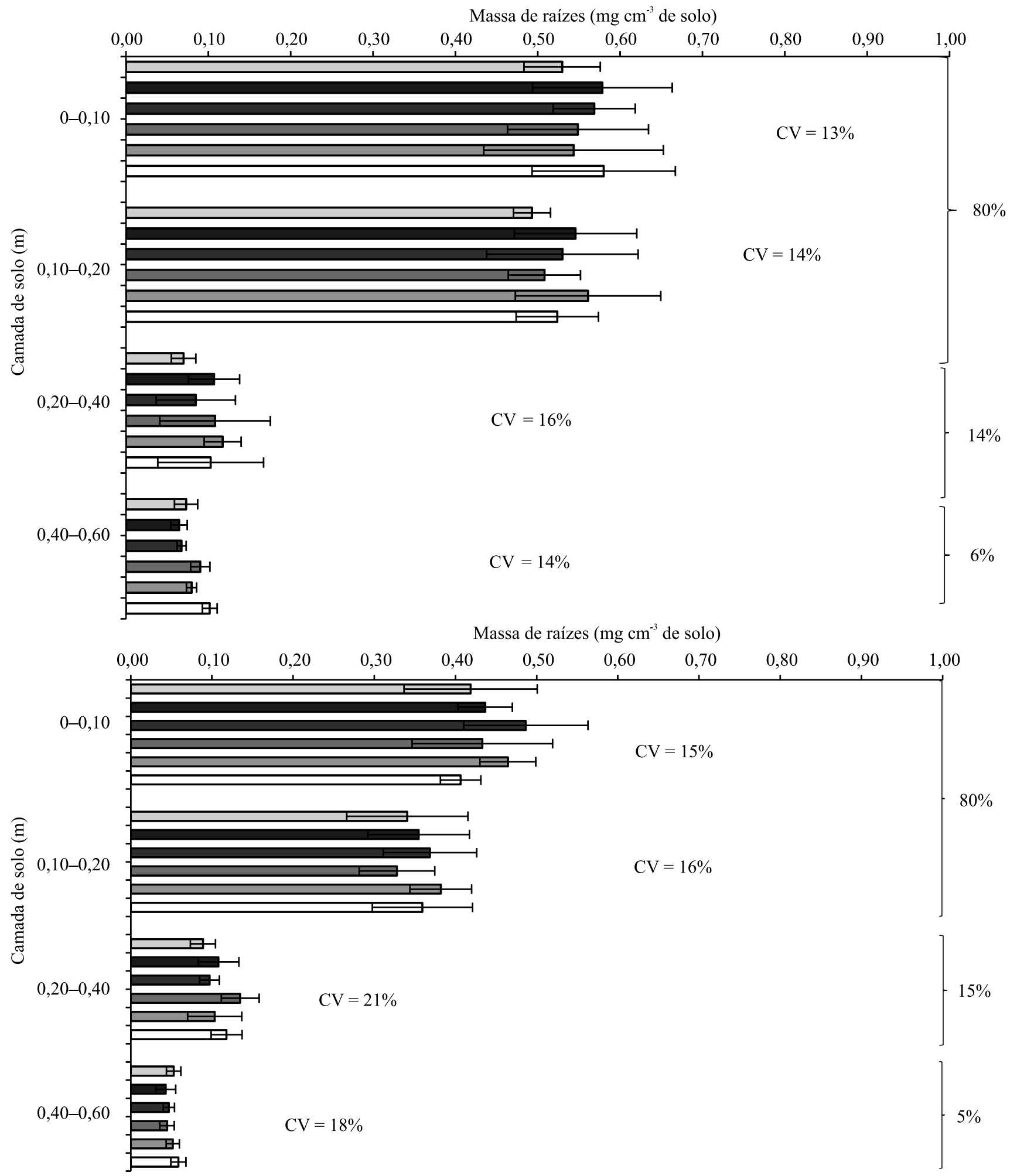

\section{Queima $100 \% \quad \bigcirc 75 \% \quad \bigcirc 50 \% \quad \bigcirc 25 \% \quad \bigcirc 0 \%$}

Figura 4. Massa de matéria seca de raízes da segunda soqueira, às distâncias 0,45 (A) e $0,75 \mathrm{~m}$ (B) da touceira, aos $300 \mathrm{DAC}$, nas camadas $0-0,10,0,10-0,20,0,20-0,40$ e $0,40-0,60 \mathrm{~m}$, e percentagem média de distribuição de raízes no perfil avaliado. Médias seguidas de letras iguais não diferem entre si, pelo teste Tukey, a 5\% de probabilidade. 
75 e $100 \%$ de palhada mantiveram estáveis as massas de raízes, em ambas as distâncias e épocas. Cury et al. (2014), ao avaliar a massa radicular $\left(\mathrm{em} \mathrm{Mg} \mathrm{ha}^{-1}\right) \mathrm{da}$ cana-de-açúcar em sistema convencional e plantio direto, verificaram que a variação da quantidade de raízes foi mais influenciada pela condição hídrica do solo, o que ressalta a importância de manejos que proporcionem menor perda e maior retenção de água no solo. Os autores verificaram ainda que a maior quantidade de raiz foi determinada no máximo excedente hídrico, e a menor, na época de reposição hídrica do solo. O tratamento plantio direto manteve a massa radicular com menor variação ao longo das épocas de amostragem.

Houve efeito da palhada quanto à produtividade na primeira soqueira, em que ocorreu deficiência hídrica até os 180 DAC (Figura 5). As quantidades 50 e $75 \%$ de palhada não diferiram entre si e apresentaram as maiores médias de produção $\left(194,30\right.$ e $193,67 \mathrm{Mg} \mathrm{ha}^{-1}$, respectivamente), $43 \%$ a mais do que o tratamento cana queimada $\left(110,33 \mathrm{Mg} \mathrm{ha}^{-1}\right)$. Apesar de não diferirem estatisticamente, os tratamentos 50 e $75 \%$ de palhada proporcionaram produção $24 \%$ maior em relação aos tratamentos de 0 e $25 \%$ de palhada. Na segunda soqueira, não houve efeito da palhada sobre a produtividade. Estes dados corroboram os obtidos por outros autores, que afirmam que o deficit hídrico, na fase inicial do ciclo, afeta drasticamente o rendimento da cultura e reduz algumas variáveis de crescimento, o que resulta em diminuição da massa de colmos (Silva et al., 2008; Aquino \& Medina, 2014).

A deficiência hídrica é um dos fatores de estresse que causam maiores danos nos processos fisiológicos e metabólicos das plantas e acarretam reduções de produtividade, especialmente pela redução da fotossíntese (Chaves et al., 2008). Um ligeiro ressecamento do solo, ainda que não afete as relações hídricas da parte aérea, causa aumento da concentração de ABA (ácido abscísico) produzido na coifa das raízes, o que leva ao fechamento estomático e à diminuição de substrato para fotossíntese. Interrompido o deficit hídrico, o desenvolvimento é recuperado somente nas folhas mais jovens (Chaves et al., 2008).

$\mathrm{Na}$ primeira soqueira, a estiagem prolongada, ocorrida até a metade do ciclo, proporcionou condições para que a palhada influenciasse o desenvolvimento das plantas (Figura 5), pois, um dos principais benefícios deste resíduo é promover maior infiltração e retenção de água no solo. Assim, verifica-se que a maior massa de raízes, proporcionada por quantidades acima de $50 \%$ de palhada, provavelmente em razão da manutenção de maior umidade no solo, possibilitaram que a cultura tivesse melhores condições de desenvolvimento, o que resultou em maior produtividade. Na segunda soqueira, quando as condições hídricas não foram restritivas, tanto a massa de matéria seca de raízes quanto a produtividade não diferiram entre os tratamentos (Figura 5).

Os resultados do presente trabalho corroboram os resultados de produtividade de cana-planta, sob diferentes quantidades de palhada, obtidos por Aquino \& Medina (2014) na mesma área experimental. Os autores verificaram que, com a ocorrência de severa deficiência hídrica nos estádios iniciais de desenvolvimento da cultura, os tratamentos com 10 e $15 \mathrm{Mg} \mathrm{ha}^{-1}$ (50 e 75\%) de palhada proporcionaram aumento de $25 \%$ da produtividade média, em relação aos tratamentos com menores quantidades de palhada. Resende et al. (2006) observaram que a manutenção da palhada no sistema proporcionou aumento de $28 \%$ da produção de colmos, ao longo de 12 ciclos.

No presente trabalho, em ciclo com ocorrência de estiagem, a quantidade $10 \mathrm{Mg} \mathrm{ha}^{-1}(50 \%)$ de palhada foi suficiente para promover melhorias no sistema

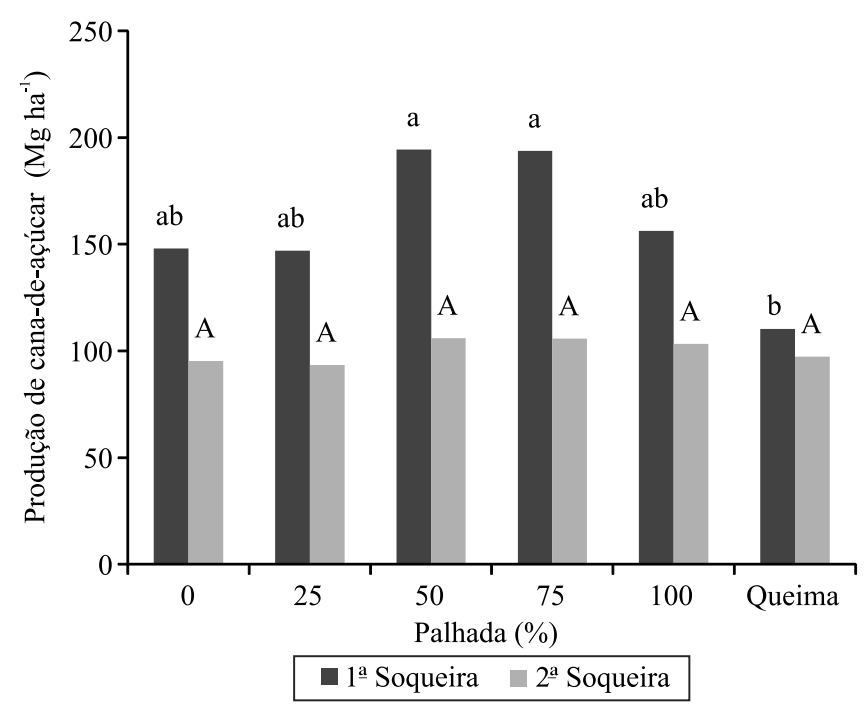

Figura 5. Produção de cana-de-açúcar em relação à percentagem de palhada em superfície, na primeira soqueira, safra $2011 / 2012$, e na segunda soqueira, safra 2012/2013. Médias seguidas de letras iguais não diferem entre si, pelo teste Tukey, a 5\% de probabilidade. Coeficiente de variação de 16 e $12 \%$ para primeira e segunda soqueira, respectivamente. 
radicular e na produtividade da cultura e, acima desse valor, não houve respostas significativas. Portanto, sem prejuízos à sustentabilidade do sistema de cultivo, o restante desse resíduo poderia ser empregado em outros setores.

A manutenção da palhada no sistema é, portanto, essencial para a produtividade da cultura e exerce importante papel na conservação do solo e na diminuição da erosão, que constitui um dos problemas ambientais mais graves atualmente, e é fundamental para a sustentabilidade do sistema de produção de cana-de-açúcar.

\section{Conclusões}

1. O sistema radicular e a produtividade da cana-de-açúcar (Saccharum officinarum) são favorecidos pela mudança no sistema de colheita de cana queimada para cana sob palhada.

2. A retirada total da palhada, a manutenção de $5 \mathrm{Mg} \mathrm{ha}^{-1}$ ou a queima da cana resultam em menor produção de massa radicular, quando há ocorrência de estiagem no período de crescimento da cana-de-açúcar.

3. A colheita com cana queimada diminui a produtividade da cana-de-açúcar, quando sucedida de período de estiagem.

4. A deposição no solo de $10 \mathrm{Mg} \mathrm{ha}^{-1}(50 \%)$ de palhada é suficiente para proporcionar aumento da produtividade da cana-de-açúcar.

5. A palhada não influencia o sistema radicular e a produtividade da cana-de-açúcar, quando há precipitação pluvial no período de crescimento da cultura.

\section{Agradecimentos}

À Petrobras (processo 6104), pelo financiamento do trabalho; à Coordenação de Aperfeiçoamento de Pessoal de Nível Superior (Capes, processo 0704932), pela concessão de bolsa de estudo; à Usina de Bandeirantes, pela cessão da área experimental e pelo apoio técnico nas avaliações; e à Embrapa Tabuleiros Costeiros, pela orientação e coordenação da pesquisa.

\section{Referências}

ACOMPANHAMENTO DA SAFRA BRASILEIRA: cana-de-açúcar. Brasília: Conab, v.1, n.4, quarto levantamento, abr. 2015. 30p.
ALVAREZ, I.A.; CASTRO, P.R. de C. e; NOGUEIRA, M.C.S. Crescimento de raízes de cana crua e queimada em dois ciclos. Scientia Agricola, v.57, p.653-659, 2000. DOI: 10.1590/ S0103-90162000000400009.

AQUINO, G.S. de; MEDINA, C. de C. Produtividade e índices biométricos e fisiológicos de cana-de-açúcar cultivada sob diferentes quantidades de palhada. Pesquisa Agropecuária Brasileira, v.49, p.173-180, 2014. DOI: 10.1590/S0100-204X2014000300003.

AZEVEDO, M.C.B. de; CHOPART, J.L.; MEDINA, C. de C. Sugarcane root length density and distribution from root intersection counting on a trench-profile. Scientia Agricola, v.68, p.94-101, 2011. DOI: 10.1590/S0103-90162011000100014.

BALL-COELHO, B.; TIESSEN, H.; STEWART, J.W.B.; SALCEDO, I.H.; SAMPAIO, E.V.S.B. Residue management effects on sugarcane yield and soil properties in Northeastern Brazil. Agronomy Journal, v.85, p.1004-1008, 1993. DOI: 10.2134/agronj1993.00021962008500050009x.

CAVENAGHI, A.L.; ROSSI, C.V.S.; NEGRISOLI, E.; COSTA, E.A.D.; VELINI, E.D.; TOLEDO, R.E.B. Dinâmica do herbicida amicarbazone (Dinamic) aplicado sobre palha de cana-de-açúcar (Saccharum officinarum). Planta Daninha, v.25, p.831-837, 2007. DOI: $10.1590 / \mathrm{S} 0100-83582007000400020$.

CHAVES, M.M.; FLEXAS, J.; PINHEIRO, C. Photosynthesis under drought and salt stress: regulation mechanisms from whole plant to cell. Annals of Botany, v.103, p.551-560, 2008. DOI: 10.1093/aob/men125.

CHRISTOFFOLETI, P.J.; CARVALHO, S.J.P. de; LÓPEZ-OVEJERO, R.F.; NICOLAI, M.; HIDALGO, E.; SILVA, J.E. da. Conservation of natural resources in Brazilian agriculture: implications on weed biology and management. Crop Protection, v.26, p.383-389, 2007. DOI: 10.1016/j.cropro.2005.06.013.

CLAESSEN, M.E.C. (Org.). Manual de métodos de análise de solo. 2.ed. Rio de Janeiro: EMBRAPA-CNPS, 1997. 212p. (EMBRAPA-CNPS. Documentos, 1).

COSTA, C.T.S.; FERREIRA, V.M.; ENDRES, L.; FERREIRA, D.T. da R.G.; GONÇALVES, E.R. Crescimento e produtividade de quatro variedades de cana-de-açúcar no quarto ciclo de cultivo. Revista Caatinga, v.24, p.56-63, 2011.

COSTA, L.G.; MARIN, F.R.; NASSIF, D.S.P.; PINTO, H.M.S.; LOPES-ASSAD, M.L.R.C. Simulação do efeito do manejo da palha e do nitrogênio na produtividade da cana-de-açúcar. Revista Brasileira de Engenharia Agrícola e Ambiental, v.18, p.469-474, 2014. DOI: $10.1590 / \mathrm{S} 1415-43662014000500001$.

COSTA, M.C.G.; MAZZA, J.A.; VITTI, G.C.; JORGE, L. de A.C. Distribuição radicular, estado nutricional e produção de colmos e de açúcar em soqueiras de dois cultivares de cana-de-açúcar em solos distintos. Revista Brasileira Ciências do Solo, v.31, p.1503-1514, 2007. DOI: $10.1590 / \mathrm{S} 0100-06832007000600027$.

CURY, T.N.; DE MARIA, I.C.; BOLONHEZI, D. Biomassa radicular da cultura de cana-de-açúcar em sistema convencional e plantio direto com e sem calcário. Revista Brasileira de Ciência do Solo, v.38, p.1929-1938, 2014. DOI: 10.1590/ S0100-06832014000600027.

FERNANDES, A.C. Terceira geração de variedades de cana-deaçúcar. São Paulo: Copersucar, 1991. 27p. (Boletim técnico). 
GARCIA, J.F.; GRISOTO, E.; BOTELHO, P.S.M.; PARRA, J.R.P.; APPEZZATO-DA-GLÓRIA, B. Feeding site of the spittlebug Mahanarva fimbriolata (Stål) (Hemiptera: Cercopidae) on sugarcane. Scientia Agricola, v.64, p.555-557, 2007. DOI: 10.1590/S0103-90162007000500014.

GUIMARÃES, E.R.; MUTTON, M.A.; MUTTON, M.J.R.; FERRO, M.I.T.; RAVANELI, G.C.; SILVA, J.A. da. Free proline accumulation in sugarcane under water restriction and spittlebug infestation. Scientia Agricola, v.65, p.628-633, 2008. DOI: 10.1590/S0103-90162008000600009.

LACLAU, P.B.; LACLAU, J.-P. Growth of the whole root system for a plant crop of sugarcane under rainfed and irrigated environments in Brazil. Field Crops Research, v.114, p.351-360, 2009. DOI: 10.1016/j.fcr.2009.09.004.

LIMA, M.A.P.; NATALENSE, A.P.P. Necessidade de pesquisa básica para cana e etanol. In: CORTEZ, L.A.B. Bioetanol de cana-de-açúcar. São Paulo: Blusher, 2010. p.150-156.

PAULINO,A.F.; MEDINA, C.C.; AZEVEDO, M.C.B.; SILVEIRA, K.R.P.; TREVISAN, A.A.; MURATA, I.M. Escarificação de um Latossolo Vermelho na pós-colheita de soqueira de cana-de-açúcar. Revista Brasileira de Ciência do Solo, v.28, p.911-917, 2004. DOI: $10.1590 / \mathrm{S} 0100-06832004000500013$.

RESENDE, A.S. de; SANTOS, A.; XAVIER, R.P.; COELHO, C.H.; GONDIM, A.; OLIVEIRA, O.C.; ALVES, B.J.R.; BODDEY, R.M.; URQUIAGA, S. Efeito da queima da palhada da cana-de-açúcar e de aplicações de vinhaça e adubo nitrogenado em características tecnológicas da cultura. Revista Brasileira de Ciências do Solo, v.30, p.937-941, 2006. DOI: 10.1590/S0100-06832006000600003.
SANTOS, H.G. dos; JACOMINE, P.K.T.; ANJOS, L.H.C. dos; OLIVEIRA, V.A. de; LUMBRERAS, J.F.; COELHO, M.R.; ALMEIDA, J.A. de; CUNHA, T.J.F.; OLIVEIRA, J.B. de. Sistema brasileiro de classificação de solos. 3.ed. Brasília: Embrapa, 2013. 353p.

SILVA, M. de A; JERONIMO, E.M.; LÚCIO, A.D. Perfilhamento e produtividade de cana-de-açúcar com diferentes alturas de corte e épocas de colheita. Pesquisa Agropecuária Brasileira, v.43, p.979-986, 2008. DOI: 10.1590/S0100-204X2008000800005.

SMITH, D.M.; INMAN-BAMBER, N.G.; THORBURN, P.J. Growth and function of the sugarcane root system. Field Crops Research, v.92, p.169-183, 2005. DOI: 10.1016/j.fcr.2005.01.017.

SOUZA, Z.M. de; PAIXÃO, A.C.S.; PRADO, R. de M.; CESARIN, L.G.; SOUZA, S.R. de. Manejo de palhada de cana colhida sem queima, produtividade do canavial e qualidade do caldo. Ciência Rural, v.35, p.1062-1068, 2005a. DOI: 10.1590/ S0103-84782005000500012.

SOUZA, Z.M. de; PRADO, R.M.; PAIXAO, A.C.S.; CESARIN, L.G. Sistemas de colheita e manejo da palhada de cana-de-açúcar. Pesquisa Agropecuária Brasileira, v.40, p.271-278, 2005b. DOI: 10.1590/S0100-204X2005000300011.

TAVARES, O.C.H.; LIMA, E.; ZONTA, E. Crescimento e produtividade da cana planta cultivada em diferentes sistemas de preparo do solo e de colheita. Acta Scientiarum. Agronomy, v.32, p.61-68, 2010. DOI: 10.4025/actasciagron.v32i1.2051.

THORNTHWAITE, C.W.; MATHER, J.R. The water balance. New Jersey: Drexel Institute of Technology, 1955. 104p.

Recebido em 21 de maio de 2015 e aprovado em 21 de outubro de 2015 